\title{
The aetiology of community associated pneumonia in children in Nanjing, China and aetiological patterns associated with age and season
}

\author{
Keping Chen ${ }^{1 *}$, Runqing Jia ${ }^{2}$, Li Li ${ }^{1}$, Chuankun Yang ${ }^{1}$ and Yan Shi $^{1}$
}

\begin{abstract}
Background: Viral and atypical bacterial pathogens play an important role in respiratory tract infection. Using the Pneumoslide IgM test, the presented study explored the aetiology of community-acquired pneumonia and investigated further whether there was an association between age or season and aetiological organisms.

Methods: Serum samples, taken between August 2011 and August 2013, from patients with CAP were tested with the Pneumoslide IgM kit. The Pneumoslide IgM technology can simultaneously diagnose 9 viral and atypical bacterial pathogens: Legionella pneumophila serogroup 1 (LP1), Mycoplasma pneumoniae (MP), Coxiella burnetii (COX), Chlamydophila pneumonia (CP), Adenovirus (ADV), Respiratory syncytial virus (RSV), Influenza A (INFA), Influenza B (INFB), Parainfluenza 1, 2 and 3 (PIVs). The data was analyzed by using Statistical Package for the Social Sciences for Windows (SPSS, version 11.0).

Results: Of a total of 1204 serum samples tested, 624 samples were positive. M. pneumoniae was the dominant pathogen, with INFB, PIVs, and RSV ranking second to fourth, respectively. The positive percentages of MP, INFB, PIVs and RSV were found to be associated with age, especially MP, INFB and PIVs. The positive percentages of MP, PIVs and RSV were also found to be associated with season. The positive percentage of MP in autumn was the highest. The positive percentages of LP1 in August and September, ADV in June and INFB in March were relatively higher than that in other months.

Conclusions: The results show there were 4 main viral and atypical bacterial pathogens causing CAP in our study. Some pathogens were found to be associated with age and season. M. pneumoniae was the most predominant pathogen among these 9 pathogens. It is necessary to take preventative measures in order to prevent the spread of these pathogens in susceptible age groups during peak season.
\end{abstract}

Keywords: Community-acquired pneumonia, Aetiology, M. pneumoniae, Pneumoslide IgM

\section{Background}

Community-acquired pneumonia (CAP) refers to pneumonia acquired outside of a health care facility. In the United States, CAP is the number-one cause of death from infection and the sixth leading cause of death overall. Each year, it is responsible for about 4.2 million outpatient visits and more than 60,000 deaths [1,2]. It is important to understand the possible causes of CAP and which are most likely to occur so that appropriate

\footnotetext{
* Correspondence: keping2001@hotmail.com

'Zhongda Hospital, Southeast University, 87 Dingjiaqiao, Nanjing 210009, Jiangsu, China

Full list of author information is available at the end of the article
}

therapies can be selected. The primary pathogens responsible for CAP broadly include typical bacterial pathogens, atypical bacterial pathogens and viruses [3]. With the development of new laboratory testing technologies in recent years, it was found that the roles of viral and atypical bacterial pathogens in respiratory tract infection were underestimated. Research shows that about $33.3 \%$ of CAP cases are caused by viral and atypical bacterial pathogens [4]. Choi, et al. studied 198 patients with pneumonia and the determination was that $35 \%$ of the patients had a bacterial infection and $36 \%$ had viral infection [5]. In 2010, pneumonia was ranked in the United States as the sixth leading cause of 
death in children 1 to 4 years of age [6]. It is estimated that for every 1000 infants and children in North America and Europe, 35 to 40 will be affected by CAP [7]. Viral pathogens are the most common cause of CAP in children younger than 2 years of age, accounting for $80 \%$ of cases [8].

The prevalence of each pathogen varies from country to country and could be due to differences in seasons and geographic areas. Nanjing is the provincial capital of Jiangsu, and is a metropolitan area with a population greater than 7 million people, so exploring the aetiology of pneumonia in Nanjing is significant for the health of local children because of their immature and susceptible immune defenses.

A rapid and standardized diagnostic method for the detection of pathogens in children with CAP is important. The currently validated methods to define the etiology of infection are serology, cell culture and PCR. Viral culture can also be employed for most of the respiratory viruses, but the need for specific culture medium and the lengthy diagnosis times are substantial disadvantages [4]. Recently, PCR has been reported as a rapid method with high sensitivity that may exceed that of culture, but PCR assays need specialized equipment and the reagents are expensive [9]. Much research shows that the Pneumoslide IgM test is a reasonably sensitive, highly specific, easy, rapid and cost-effective technique for detection of viral or atypical bacterial pathogens [10]. As an indirect immunofluorescense technique for IgM detection, Pneumoslide IgM can simultaneously diagnose 9 pathogens of infectious disease of the respiratory tract, including the Legionella pneumophila serogroup 1 (LP1), Mycoplasma pneumoniae (MP), Coxiella burnetii (COX), Chlamydophila pneumoniae (CP), Adenovirus (ADV), Respiratory syncytial virus (RSV), Influenza A (INFA), Influenza B (INFB), Parainfluenza 1,2 and 3 (PIVs). Pneumoslide IgM could detect virus in $25 \%$ of patients, whereas viral culture detected only in $16.7 \%$. Sally compared the technique with PCR, and reported the sensitivity and specificity of Pneumoslide IgM for RSV was $75 \%$ and $98.1 \%$, respectively, whereas they were $78 \%$ and $95 \%$ for M. pneumoniae, respectively [10]. So Pneumoslide IgM had reasonable sensitivity and specificity for detection pathogens causing CAP. The presented investigation studies the aetiology of CAP treated in Zhongda Hospital and further investigates whether there was an association between age or season and the aetiological organism, which can assist in planning better therapeutic and prevention strategies to prevent the spread of the aetiological organism in susceptible age groups during peak season.

\section{Methods}

\section{Subject information}

The study was conducted on 1204 children patients suffering from CAP recruited from Zhongda Hospital,
Southeast University, Nanjing, China. Written informed consent was obtained from all participants' guardians. The study was approved by the Human Investigation Review Committee at Zhongda Hospital Affiliated to Southeast University. Diagnosis of pneumonia followed World Health Organization Criteria (1994). All of the child patients showed signs and symptoms of pneumonia caused by an infection that had been acquired outside the hospital.

Of the patients, 715 children were male and 489 were female. Aged $4 \mathrm{~h}$ after birth to 14 years old, children were divided into four groups: infants group (newborn $\sim 1$ year old), 184 cases; toddlers group ( $>1 \sim 3$ years old), 477 cases; preschool group ( $>3 \sim 6$ years old), 403 cases; school children group $(7 \sim 14$ years old), 140 cases. Table 1 shows the socio-demographic profile of the children in this study. Serums samples of patients were separated from venous blood drawn from every child and tested with Pneumoslide IgM to explore the aetiology of CAP. According to the seasons when the Pneumoslide IgM tests were performed, all the subjects were divided into four group: spring group (March, April and May), 316 cases; summer group (June, July and August), 295 cases; autumn group (September, October and November), 227 cases; winter group (January, February and December), 366 cases. The data was analyzed by using the Statistical Package for the Social Sciences for Windows (SPSS, version 11.0) to determine whether there was an association between age or season and the aetiological organism, and a $\mathrm{p}$ value $<0.05$ was considered to be statistically significant.

\section{Blood sampling}

Four milliliters of venous blood was drawn from each child. The samples were centrifuged at $2000 \mathrm{~g}$ for $10 \mathrm{~min}$ at $4^{\circ} \mathrm{C}$. Serum was separated and stored at $-20^{\circ} \mathrm{C}$ until assayed with the Pneumoslide IgM test.

\section{Pneumoslide IgM test (Vircell-slide, Granada, Spain)}

Each slide has 10 wells with each well containing one of the following antigens: Legionella pneumophila serogroup 1 (LP1), Mycoplasma pneumoniae (MP), Coxiella burnetii (COX), Chlamydophila pneumoniae (CP), Adenovirus (ADV), Respiratory syncytial virus (RSV), Influenza A (INFA), Influenza B (INFB), Parainfluenza 1, 2 and 3

Table 1 Socio-demographic profile of the study children

\begin{tabular}{llll}
\hline Age group & Age & $\begin{array}{l}\text { Place of } \\
\text { schooling }\end{array}$ & $\begin{array}{l}\text { House } \\
\text { condition }\end{array}$ \\
\hline Infants group & $\begin{array}{l}\text { newborn } \sim 1 \\
\text { year old }\end{array}$ & at home & spacious \\
toddlers group & $>1 \sim 3$ years old & at home & spacious \\
preschooler group & $>3 \sim 6$ years old & In daycare & crowded \\
school children & $7 \sim 14$ years old & In boarding school & crowded \\
\hline
\end{tabular}


Table 2 The positive percentages of 9 pathogens

\begin{tabular}{lcc}
\hline Pathogens & Number & Positive percentage (\%) \\
\hline Mycoplasma pneumonia (MP) & 491 & 40.78 \\
Influenza B (INFB) & 85 & 7.06 \\
Parainfluenza 1, 2 and 3 (PIVs) & 58 & 4.82 \\
Respiratory syncytial virus (RSV) & 40 & 3.32 \\
Adenovirus (ADV) & 13 & 1.08 \\
Legionella pneumophilasero & 11 & 0.91 \\
group 1 (LP1) & & \\
Chamydophila pneumonia (CP) & 4 & 0.33 \\
Coxiellaburnetii (COX) & 1 & 0.08 \\
Influenza A (INFA) & 1 & 0.08 \\
\hline
\end{tabular}

(PIVs) and a cell control. Serum samples were diluted 1:1 with phosphate buffered saline (PBS), and then treated with anti-human IgG sorbent. The sorbent-treated diluted serum was incubated $90 \mathrm{~min}$ at $37^{\circ} \mathrm{C}$ with the 10 slide wells. The slide was washed twice with PBS before the fluorescent secondary IgM antibody was added to the wells and incubated at $37^{\circ} \mathrm{C}$ for 30 minutes. The slide was washed twice with PBS and the greenish-yellow fluorescent signal was detected with a fluorescence microscope (Zeiss, Oberkochen, Germany).

\section{Results}

The positive percentage of 9 pathogens

Of a total of 1204 samples tested, 624 samples were positive for a positive percentage of $51.83 \%$. The most predominant pathogen was M. pneumoniae, with a positive percentage of $40.78 \%$. The pathogens ranking second to fourth place were INFB, PIVs, and RSV, with positive percentages of $7.06 \%, 4.82 \%$, and $3.32 \%$, respectively. Among all of the samples, only 1 COX and 1 INFA infection were detected (Table 2).

\section{The positive percentages of pathogens isolated from different age groups}

As a whole, the positive percentages of the 9 pathogens were $24.45 \%$ in infants, $47.38 \%$ in toddlers, $79.40 \%$ in preschoolers and $80.71 \%$ in school aged children. The positive percentages of viral and atypical bacterial pathogens increased with the rising ages of children. For the 4 major pathogens, the positive percentages of MP, INFB, PIVs and RSV were found to be associated with age, with $\mathrm{p}$ values of $<0.001,<0.001,<0.001$, and 0.038 , respectively. M. pneumoniae was the most predominant pathogen in all age groups, compared to other pathogens. The positive percentages of MP and INFB in preschooler group were $55.33 \%$ and $12.41 \%$, which were the highest, compared to other age groups, but the positive percentages of these two pathogens were just $13.04 \%$ and $2.17 \%$ in infants group. The positive percentage of PIVs in school children group was higher than that in other age groups and it was seen that the positive percentages increased with the age of patients $(0.54 \%$ in infants group; $1.68 \%$ in toddlers group; $8.19 \%$ in preschool group; $11.43 \%$ in school group) (Table 3 ).

\section{The positive percentages of pathogens isolated from different seasons}

Among the 4 major respiratory tract pathogens, the positive percentages of MP, PIVs and RSV were found to be associated with seasons (MP, $\mathrm{p}=0.011$; PIVs, $\mathrm{p}=0.009$; RSV, $\mathrm{p}=0.038$ ) but the positive percentage of INFB was not found to be associated with season $(\mathrm{p}=0.063)$ (Table 4). The positive percentage of MP was always high throughout the seasons (>29.63\%) (Figure 1), compared to the other 8 pathogens. The positive percentages of MP was relatively high in summer and autumn (45.08\% and $47.14 \%$ respectively) and relatively low in spring and winter $(38.29 \%$ and $35.52 \%$ respectively) (Table 4). The positive percentages of LP1

Table 3 The positive percentages of pathogens isolated from different age groups with PneumoslidelgM test

\begin{tabular}{|c|c|c|c|c|c|c|}
\hline Pathogens & Infants (\%) $\mathrm{N}=184$ & Toddlers (\%) N = 477 & Preschooler (\%) $\mathrm{N}=403$ & School children (\%) $N=140$ & $x^{2}$ & $P$ \\
\hline$\overline{\mathrm{MP}}$ & $24(13.04)$ & $169(35.43)$ & $223(55.33)$ & $75(53.57)$ & 109.105 & $<0.001$ \\
\hline INFB & $4(2.17)$ & 19 (3.98) & $50(12.41)$ & $12(8.57)$ & 31.624 & $<0.001$ \\
\hline PIVs & $1(0.54)$ & $8(1.68)$ & $33(8.19)$ & $16(11.43)$ & 40.923 & $<0.001$ \\
\hline RSV & $11(5.98)$ & 19 (3.98) & $7(1.74)$ & $3(2.14)$ & 8.450 & 0.038 \\
\hline ADV & $4(2.17)$ & $5(1.05)$ & $3(0.74)$ & $1(0.71)$ & & \\
\hline LP1 & $0(0.00)$ & $6(1.26)$ & $4(0.99)$ & $1(0.71)$ & & \\
\hline $\mathrm{CP}$ & $0(0.00)$ & $0(0.00)$ & $0(0.00)$ & $4(2.86)$ & & \\
\hline $\operatorname{cox}$ & $1(0.54)$ & $0(0.00)$ & $0(0.00)$ & $0(0.00)$ & & \\
\hline INFA & $0(0.00)$ & $0(0.00)$ & $0(0.00)$ & $1(0.71)$ & & \\
\hline
\end{tabular}

MP: Mycoplasma pneumonia; INFB: Influenza B; PIVs: Parainfluenza 1, 2 and 3; RSV: Respiratory syncytial virus; ADV: Adenovirus; LP1: Legionella pneumophilaserogroup 1; CP: Chamydophila pneumonia; COX: Coxiellaburnetii; INFA: Influenza A. 
Table 4 The positive percentages of pathogens isolated from different seasons with PneumoslidelgM test

\begin{tabular}{|c|c|c|c|c|c|c|}
\hline Pathogens & Spring (\%) N= 316 & Summer (\%) N= 295 & Autumn (\%) N = 227 & Winter (\%) $N=366$ & $x^{2}$ & $\mathbf{P}$ \\
\hline $\mathrm{MP}$ & $121(38.29)$ & $133(45.08)$ & $107(47.14)$ & $130(35.52)$ & 11.067 & 0.011 \\
\hline INFB & $30(9.49)$ & $14(4.75)$ & $20(8.81)$ & $21(5.74)$ & 7.296 & 0.063 \\
\hline PIVs & $23(7.28)$ & $12(4.07)$ & $15(6.61)$ & $8(2.19)$ & 11.651 & 0.009 \\
\hline RSV & $14(4.43)$ & $3(1.02)$ & $6(2.64)$ & $17(4.64)$ & 8.408 & 0.038 \\
\hline ADV & $4(1.27)$ & $6(2.03)$ & $1(0.44)$ & $2(0.55)$ & & \\
\hline LP1 & $2(0.63)$ & $4(1.36)$ & $3(1.32)$ & $2(0.55)$ & & \\
\hline $\mathrm{CP}$ & $0(0.00)$ & $1(0.34)$ & $3(1.32)$ & $0(0.00)$ & & \\
\hline $\operatorname{cox}$ & $0(0.00)$ & $0(0.00)$ & $1(0.44)$ & $0(0.00)$ & & \\
\hline INFA & $1(0.32)$ & $0(0.00)$ & $0(0.00)$ & $0(0.00)$ & & \\
\hline
\end{tabular}

MP: Mycoplasma pneumonia; INFB: Influenza B; PIVs: Parainfluenza 1, 2 and 3; RSV: Respiratory syncytial virus; ADV: Adenovirus; LP1: Legionella pneumophilaserogroup 1; CP: Chamydophila pneumonia; COX: Coxiellaburnetii; INFA: Influenza A.

Spring includes Mar, Apr, and May; summer includes Jun, Jul, and Aug; autumn includes Sep, Oct and Nov; winter includes Jan, Feb and Dec.

in August and September and of ADV in June were higher than in other months (Figures 2 and 3).

\section{The mixed infection among these respiratory tract pathogens}

Of the 1204 samples tested, 79 were confirmed as mixed infection, for a $6.56 \%$ positive percentage. Generally, there were four major mixed infection types. There were 35 samples infected with MP and INFB (44.30\% positive percentage) and $36.71 \%$ of these samples infected with MP and PIVs. Other mixed infection types were MP with RSV and INFB with PIVs. Sally, et al. found that MP often participated in mixed infections, and, according to one of their hypotheses, patients infected with MP may be susceptible to other infectious pathogens [10]. However, neither the present study nor previous findings could explain these results, so further research is needed to elucidate the question.

\section{Discussion}

Some pathogens may have a higher seasonal incidence than others in certain geographic areas, and the diagnosis of those causing prevalent diseases would be of value. It was therefore important to know the aetiology of

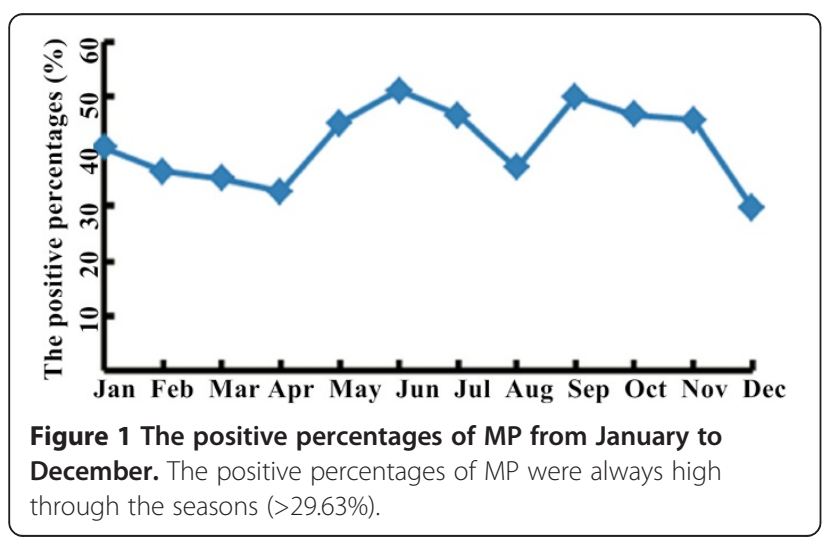

pneumonia in Nanjing, and to determine whether there was an association between age or season and aetiological organism. Among children in Nanjing, there were 4 major viral and atypical bacterial pathogens causing CAP that were detected with the Pneumoslide IgM test. $M$. pneumoniae was the most predominant pathogen in different age and seasonal groups, which did not agree with previous results. Ren, et al. found that INF was the most predominant pathogen among the Beijing population [11], although this difference may result from the different geographic area and different population. MP is highly contagious and can spread between people through bodily fluids and airborne droplets from sneezing and coughing. It was most easily spread among people who were in close contact with one another [12]. In China, children go to daycare when they are about 3 years old and go to primary school when they are about 7 years old. Compared to the spacious house conditions for infants and toddlers, the preschool and school-aged children lived or studied in densely populated (crowded) spaces because of the large population (Table 1) and MP was most easily spread among children. Our results showed a significant association among age groups $(\mathrm{p}<0.01)$ (Table 3$)$.

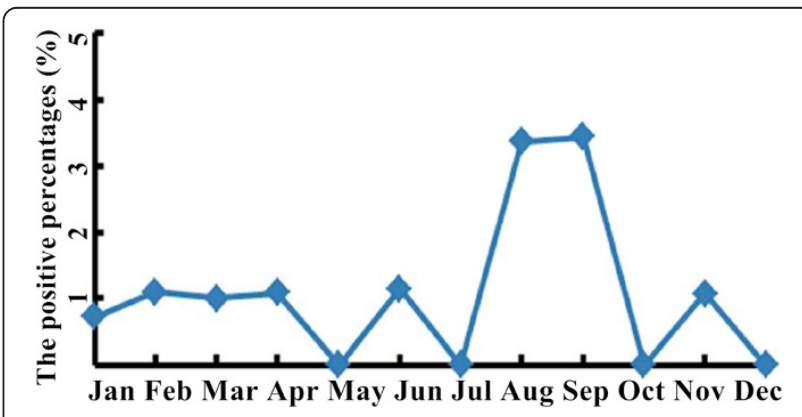

Figure 2 The positive percentages of LP1 from January to December. The positive percentages of LP1 in August and September were higher than in other months. 


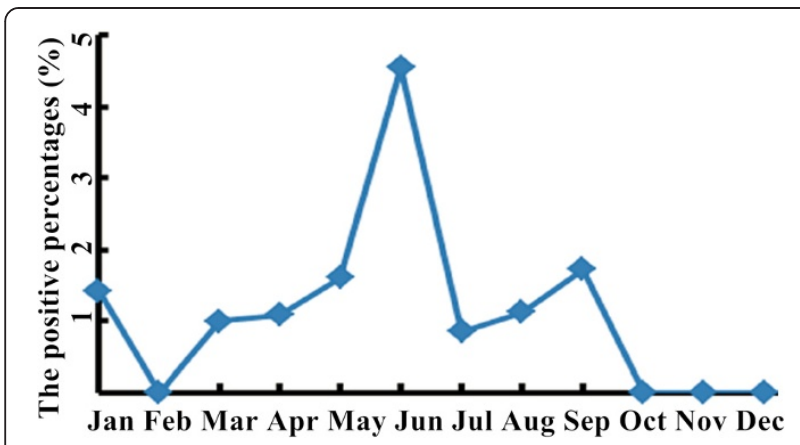

Figure 3 The positive percentages of ADV from January to

December. The positive percentages of ADV in June were higher than in other months.

The positive percentages of MP in the preschool and school groups were higher than the infants or toddlers groups. Although MP infections can occur at any time of year, they were most common in the late summer and autumn. Our results confirmed the epidemiological characteristics of MP; the positive percentages of MP in summer and autumn were $45.08 \%$ and $47.14 \%$, respectively, and MP was significantly associated with seasons $(\mathrm{p}<0.01)$ (Table 4). Patients with MP infection may be susceptible to infection with other pathogens, resulting in mixed infections, such as MP with INFB or MP with PIVs. When treating a mixed infection, particular attention must be paid to the characteristics of the infection and the responsible pathogens.

Influenza is an RNA virus of the orthomyxoviridae family and has three serotypes (A, B, and C) which have been described $[13,14]$. In the samples tested, only 1 INFA positive was detected. However 85 samples infected with INFB were detected in these same subjects (Table 2). INFB usually causes disease in populations confined to closed spaces, such as daycare centers and boarding schools [15]. Our results show the positive percentages of INFB in the preschool and school children groups were higher than that in the infants and toddlers groups $(\mathrm{p}<0.01)$ (Table 3$)$.

PIVs can spread from person to person through close contact [16,17]. Like MP and INFB, children who lived in crowed space (such as daycare and boarding school conditions) were susceptible to infect with PIVs ( $\mathrm{p}<$ 0.01) (Table 3). PIVs infections are most common in the spring, summer and fall, and our results were concordant with the characteristics of PIVs $(\mathrm{p}<0.01)$ (Table 4).

RSV was the most common viral cause of lower respiratory infections in children, especially children younger than 2 years, and was rarely diagnosed in adults $[8,18,19]$. Our results show a higher association for RSV infection among the infants and toddlers groups $(\mathrm{p}<0.05)$, although the positive percentages of
RSV in the infants and toddlers groups were only $5.98 \%$ and 3.98 , respectively (Table 3 ). RSV was found to be associated with season $(\mathrm{p}<0.05)$ and the positive percentages of RSV were higher in the spring and winter seasons (Table 4).

\section{Conclusions}

As observed in our results, there were 4 major viral and atypical bacterial pathogens causing CAP, and some pathogens were found to be associated with age and season. M. pneumoniae was the dominant pathogen. Crowed spaces (daycare, boarding school, etc.) may be the major reason for the spread of MP, INFB, and PIVs among children in Nanjing. The study accumulated valuable data about the aetiology and epidemiology of CAP among children in Nanjing, not only increasing the knowledge base of the aetiology of CAP, but also assisting in better planning of therapeutic and prevention strategies to prevent the spread of the pathogens in susceptible age groups during peak season.

\section{Limitation}

The Pneumoslide IgM test has reasonable sensitivity and specificity for the detection of pathogens. However, the test could not detect bacterial pathogens and, therefore, the aetiology presented by the study were only for viral and atypical bacterial pathogens causing community-acquired pneumonia. In order to improve the positive percentages of detection for $\mathrm{CP}$ and $\mathrm{COX}$, multiple serum samples with different sampling times can be tested to account for the later increase in antibody levels, compared to other pathogens.

\section{Competing interests}

The authors declare that they have no competing interests.

\section{Authors' contributions}

KC conceived and designed the experiments. KC and YS prepared the serum and performed the Pneumoslide IgM test. KC, RJ, CY, and LL analyzed the data. KC wrote the paper. All authors read and approved the final manuscript.

\section{Acknowledgments}

We are deeply appreciative of the study participants. The work was partly supported by the national natural science foundation of China (No. 81200877).

\section{Author details}

${ }^{1}$ Zhongda Hospital, Southeast University, 87 Dingjiaqiao, Nanjing 210009, Jiangsu, China. ${ }^{2}$ College of Life Sciences and Bioengineering, Beijing University of Technology, 100 Ping Le Yuan, Beijing 100022, China.

Received: 29 August 2014 Accepted: 15 January 2015

Published online: 10 February 2015

\section{References}

1. Mortensen EM, Kapoor WN, Chang CC, Fine MJ. Assessment of mortality after long-term follow-up of patients with community-acquired pneumonia. Clin Infect Dis. 2003;37:1617-24.

2. File Jr TM, Marrie TJ. Burden of community-acquired pneumonia in North American adults. Postgrad Med. 2010;122:130-41. 
3. Haessler S, Schimmel JJ. Managing community-acquired pneumonia during flu season. Cleve Clin J Med. 2012;79(1):67-78.

4. Jennings LC, Anderson TP, Beynon KA, Chua A, Laing RT, Werno AM, et al. Incidence and characteristics of viral community-acquired pneumonia in adults. Thorax. 2008;63(1):42-8.

5. Choi SH, Hong SB, Ko GB, Lee Y, Park HJ, Park SY, et al. Viral infection in patients with severe pneumonia requiring intensive care unit admission. Am J Respir Crit Care Med. 2012;186:325-32.

6. Murphy SL, Xu JQ, Kochanek KD. Deaths: Preliminary data for 2010. National Vital Statistics Reports. 2012;60(4):1-52.

7. Centers for Disease Control and Prevention. Pneumonia Can Be PreventedVaccines Can Help. [http://www.cdc.gov/features/pneumonia] January 17, 2012.

8. Bradley JS, Byington CL, Shah SS, Alverson B, Carter ER, Harrison C, et al. The management of community-acquired pneumonia in infants and children older than 3 months of age: clinical practice guidelines by the Pediatric Infectious Diseases Society and the Infectious Diseases Society of America. Clin Infect Dis. 2011;53(7):e25-76.

9. Syrmis MW, Whiley DM, Thomas M, Mackay IM, Williamson J, Siebert DJ, et al. A sensitive, specific, and cost-effective multiplex reverse transcriptase-PCR assay for the detection of seven common respiratory viruses in respiratory samples. J Mol Diagn. 2004;6(2):125-31.

10. El-Sahrigy SAF, Abdel-Rahman AMO, Abou Shady EAE, Attia HR, Gomaa HE, Pneumoslide-M Technique for Rapid Detection of Atypical Pathogens in Critically III Children with Lower Respiratory Tract Infections. J Med Sci. 2006;6:793-9.

11. Ren $L$, Gonzalez R, Wang Z, Xiang Z, Wang Y, Zhou H, et al. Prevalence of human respiratory viruses in adults with acute respiratory tract infections in Beijing, 2005-2007. Clin Microbiol Infect. 2009;15(12):1146-53.

12. Waites KB, Talkington DF. Mycoplasma pneumoniae and its role as a human pathogen. Clin Microbiol Rev. 2004;17(4):697-728.

13. Johnstone J, Majumdar SR, Fox JD, Marrie TJ. Viral infection in adults hospitalized with community-acquired pneumonia: prevalence, pathogens and presentation. Chest. 2008;134(6):1141-8.

14. Angeles Marcos M, Camps M, Pumarola T, Antonio Martinez J, Martinez E, Mensa J, et al. The role of viruses in the aetiology of community-acquired pneumonia in adults. Antivir Ther. 2006;11(3):351-9.

15. Rocha Neto OG, Leite RF, Baldi BG. Update on viral community-acquired pneumonia. Rev Assoc Med Bras. 2013;59(1):78-84.

16. Henrickson K, Kuhn SM, Savatski LL. Epidemiology and cost of infection with human parainfluenza virus types 1 and 2 in young children. Clin Infect Dis. 1994:18(5):770-9.

17. Lewis VA, Champlin R, Englund J, Couch R, Goodrich JM, Rolston K, et al. Respiratory disease due to parainfluenza virus in adult bone marrow transplant recipients. Clin Infect Dis. 1996;23(5):1033-7.

18. Queiróz DAO, Durigon EL, Botosso VF, Ejzemberg B, Vieira SE, Mineo JR, et al. Immune response to respiratory syncytial virus in young brazilian children. Braz J Med Biol Res. 2002;35(10):1183-93.

19. Davies HD. Community-acquired pneumonia in children. Paediatr Child Health. 2003;8(10):616-9.

\section{Submit your next manuscript to BioMed Central and take full advantage of:}

- Convenient online submission

- Thorough peer review

- No space constraints or color figure charges

- Immediate publication on acceptance

- Inclusion in PubMed, CAS, Scopus and Google Scholar

- Research which is freely available for redistribution 